\title{
Immediate dentin sealing: effect of sandblasting on the layer thickness
}

\author{
Kovalsky $\mathrm{T}^{1}$, Voborna $\mathrm{I}^{1}$, Ingr $\mathrm{T}^{2,3}$, Morozova $\mathrm{Y}^{1}$, Misova $\mathrm{E}^{1}$, Hepova $^{1}$ \\ Institute of Dentistry and Oral Sciences, Olomouc, Czech Republic. tomas.kovalsky@upol.cz
}

\begin{abstract}
OBJECTIVES: The objective of this study was to observe and to measure the impact of corundum sandblasting on the thickness of the Immediate dentin sealing layer.

METHODS: 20 recently extracted molars were collected and divided randomly into two groups. A standardized preparation was performed on each tooth and the Optibond FL dentin bonding agent (Kerr, Orange, USA) was applied on the prepared surface according to the manufacturer's instructions. The surface was then partially sandblasted. RONDOflex plus 360 (KaVo, Bieberach an der Riss, Germany) and Airsonic Mini-Sandblaster (Hager\&Werken, Duisburg, Germany) were used. Microscope observations were made. RESULTS: The arithmetic mean of the Optibond FL dentin bonding agent film thickness was $48.72 \mu \mathrm{m}$ (Group $1=45.55 \mu \mathrm{m}$ and Group $2=51.88 \mu \mathrm{m}$ ). The dentin bonding agent layer thickness was reduced to the average value of $17,12 \mu \mathrm{m}$ by RONDOflex plus 360 sandblasting (Group 1). The zero value was recorded in $16 \%$ of the locations. The Airsonic Mini-Sandblaster sandblasting changed the average thickness of the dentin bonding agent layer to $13.25 \mu \mathrm{m}$ with $31 \%$ of zero values (Group 2).

CONCLUSION: The results of this research lead to a reflection on modifications of the immediate dentin sealing procedure (Tab. 4, Fig. 3, Ref. 28). Text in PDF www.elis.sk

KEY WORDS: immediate dentin sealing, dentin bonding agent, sandblasting, corundum, adhesive.
\end{abstract}

\section{Introduction}

Extensive loss of hard dental tissues in the posterior area compromises the biomechanics and aesthetics of the tooth. Direct restorations are contraindicated in favour of partial indirect restorations in these cases. Partial indirect restorations offer advantages such as: polymerization shrinkage reduction, inner stress of the tooth reduction, fracture prevention, improved marginal adaptation and prevention of microleakage $(1,2,3)$. Indirect fabrication of the restoration allows the creation of a suitable morphology using a die cast. Compared to more traditional crowns, partial indirect restorations save healthy hard tooth tissues.

Indirect partial restorations are made of composite or glasscontaining ceramics and their longevity relies heavily on the adhesive strength between the resin luting material and a substrate (dentin or resin) $(4,5)$. The biggest challenge is to create a strong adhesive bond to the exposed dentin (6). It is recommended to

${ }^{1}$ Institute of Dentistry and Oral Sciences, Faculty of Medicine and Dentistry,
Palacky University, Olomouc, Czech Republic, ${ }^{2}$ Department of Experi-
mental Physics, Faculty of Science, Palacky University, Olomouc, Czech
Republic, and ${ }^{3}$ Department of Physical Chemistry, Faculty of Science,
Palacky University, Olomouc, Czech Republic

Address for correspondence: T. Kovalsky, MDDr, Institute of Dentistry and Oral Sciences, Palackeho 12, CZ-772 00 Olomouc, Czech Republic. Phone: +420.585 .859223$

Acknowledgement: This work was supported by Student grant of Palacky University Olomouc (Project code: IGA_LF_2018_046). seal these freshly cut dentin surfaces with a dentin bonding agent (DBA) immediately following the tooth preparation $(7,8,9)$. This procedure, called Immediate dentin sealing (IDS), is reported to achieve a long-term survival of indirect partial restorations, improved bond strength, decreased microleakage and a reduced dentin sensitivity $(3,10,11,12,13,14,15,16,17)$.

The IDS layer is left on the dentin surface during the impression, temporalization and luting process and becomes a part of the tooth restoration. It is necessary to sandblast the IDS layer before the luting process. The sandblasting creates micro-retentions that allow adhesive bonding.

Corundum (aluminum oxide) powder is used for sand-blasting the IDS layer. Laboratory abrasive corundum powders are used, among other purposes, for the removal of investment materials. These powders are produced in a grain size of $50-250 \mu \mathrm{m}$. Surgery sandblasters are compatible with finer powders. The most common powder used in surgery is $50 \mu \mathrm{m}$, but the manufacturers of sandblasters offer the use of powders ranging from $27 \mu \mathrm{m}$ to $90 \mu \mathrm{m}(18,19,20)$.

Another characteristic potentially influencing the impact of sandblasting is the minimal air supply pressure requirement set by the manufacturers $(18,19,20)$.

\section{Materials and methods}

20 recently extracted and caries-free lower third molars were collected and stored in $0.1 \%$ thymol solution. Samples were 
Tab. 1. DBA layer thickness, Group 1, protected from sandblasting $(\mu \mathrm{m})$.

\begin{tabular}{ccccccccccc}
\hline Sample & 1 & 2 & 3 & 4 & 5 & 6 & 7 & 8 & 9 & 10 \\
\hline Loc. 1 & 27 & 18 & 46 & 57 & 70 & 39 & 75 & 53 & 38 & 28 \\
2 & 34 & 29 & 75 & 50 & 66 & 30 & 55 & 28 & 18 & 35 \\
3 & 20 & 28 & 60 & 39 & 43 & 27 & 39 & 51 & 29 & 78 \\
4 & 36 & 31 & 76 & 48 & 36 & 36 & 51 & 29 & 41 & 66 \\
5 & 69 & 17 & 57 & 64 & 22 & 48 & 44 & 27 & 73 & 74 \\
6 & 73 & 29 & 48 & 59 & 36 & 34 & 35 & 35 & 50 & 51 \\
7 & 32 & 31 & 48 & 41 & 25 & 49 & 43 & 43 & 69 & 53 \\
8 & 24 & 42 & 27 & 52 & 41 & 71 & 63 & 43 & 38 & 60 \\
9 & 33 & 34 & 38 & 53 & 48 & 90 & 49 & 36 & 41 & 58 \\
10 & 42 & 40 & 48 & 60 & 61 & 61 & 63 & 28 & 52 & 45 \\
\hline Mean & 39 & 29,9 & 52,3 & 52,3 & 44,8 & 48,5 & 51,7 & 37,3 & 44,9 & 54,8 \\
St Dev & 17,070 & 7,622 & 14,485 & 7,695 & 15,626 & 19,096 & 11,799 & 9,242 & 15,965 & 15,145 \\
\hline Loc
\end{tabular}

Loc. - localization, Mean - Arithmetic mean, St Dev - Statistical deviation

Tab. 2. DBA layer thickness, Group 2, protected from sandblasting $(\mu \mathrm{m})$.

\begin{tabular}{ccccccccccc}
\hline Sample & 11 & 12 & 13 & 14 & 15 & 16 & 17 & 18 & 19 & 20 \\
\hline Loc. 1 & 104 & 40 & 41 & 50 & 29 & 22 & 77 & 49 & 61 & 42 \\
2 & 95 & 55 & 35 & 61 & 31 & 26 & 43 & 58 & 70 & 63 \\
3 & 113 & 60 & 27 & 48 & 42 & 27 & 53 & 66 & 33 & 38 \\
4 & 77 & 49 & 39 & 57 & 28 & 37 & 70 & 91 & 36 & 54 \\
5 & 74 & 53 & 42 & 70 & 19 & 41 & 63 & 47 & 47 & 55 \\
6 & 100 & 69 & 56 & 41 & 42 & 37 & 48 & 55 & 60 & 51 \\
7 & 98 & 42 & 49 & 32 & 51 & 25 & 29 & 56 & 33 & 53 \\
8 & 160 & 39 & 37 & 28 & 66 & 38 & 37 & 33 & 29 & 74 \\
9 & 120 & 47 & 29 & 44 & 37 & 53 & 80 & 60 & 30 & 48 \\
10 & 89 & 43 & 36 & 35 & 18 & 22 & 48 & 81 & 41 & 51 \\
\hline Mean & 103 & 49,7 & 39,1 & 46,6 & 36,3 & 32,8 & 54,8 & 59,6 & 44 & 52,9 \\
St Dev & 23,345 & 9,155 & 8,215 & 12,682 & 13,957 & 9,548 & 16,259 & 15,813 & 14,021 & 9,617 \\
\hline
\end{tabular}

Loc. - localization, Mean - Arithmetic mean, St Dev - Statistical deviation

Tab. 3. DBA layer thickness, Group 1 (RONDOflex plus360, 3,2 bar), sandblasted ( $\mu \mathrm{m})$.

\begin{tabular}{ccccccccccc}
\hline Sample & 1 & 2 & 3 & 4 & 5 & 6 & 7 & 8 & 9 & 10 \\
\hline Loc. 1 & 21 & 0 & 12 & 28 & 12 & 16 & 40 & 13 & 0 & 23 \\
2 & 22 & 0 & 10 & 33 & 0 & 21 & 17 & 26 & 13 & 41 \\
3 & 54 & 0 & 15 & 31 & 0 & 9 & 10 & 12 & 22 & 22 \\
4 & 45 & 0 & 12 & 16 & 8 & 13 & 21 & 17 & 0 & 19 \\
5 & 19 & 28 & 20 & 12 & 16 & 18 & 37 & 22 & 0 & 16 \\
6 & 25 & 17 & 16 & 0 & 30 & 32 & 16 & 38 & 0 & 27 \\
7 & 15 & 19 & 20 & 0 & 11 & 8 & 17 & 12 & 10 & 15 \\
8 & 15 & 0 & 22 & 35 & 0 & 29 & 43 & 10 & 23 & 13 \\
9 & 27 & 0 & 20 & 29 & 23 & 24 & 22 & 10 & 30 & 14 \\
10 & 13 & 0 & 12 & 22 & 9 & 10 & 17 & 9 & 13 & 28 \\
\hline Mean & 25,6 & 6,4 & 15,9 & 20,6 & 10,9 & 18 & 24 & 16,9 & 11,1 & 21,8 \\
St Dev & 12,831 & 10,121 & 4,110 & 12,411 & 9,523 & 7,975 & 10,982 & 8,803 & 10,578 & 8,134 \\
\hline
\end{tabular}

Loc. - localization, Mean - Arithmetic mean, St Dev - Statistical deviation

Tab. 4. DBA layer thickness, Group 2 (Airsonic Mini-Sandblaster, 4 bar), sandblasted $(\mu \mathrm{m})$.

\begin{tabular}{ccccccccccc}
\hline Sample & 11 & 12 & 13 & 14 & 15 & 16 & 17 & 18 & 19 & 20 \\
\hline Loc. 1 & 13 & 12 & 0 & 0 & 13 & 21 & 35 & 14 & 17 & 22 \\
2 & 16 & 20 & 0 & 0 & 12 & 0 & 22 & 11 & 0 & 16 \\
3 & 25 & 0 & 0 & 0 & 9 & 16 & 31 & 10 & 23 & 26 \\
4 & 32 & 0 & 0 & 16 & 22 & 12 & 42 & 18 & 9 & 31 \\
5 & 14 & 0 & 0 & 23 & 27 & 0 & 22 & 20 & 0 & 12 \\
6 & 28 & 0 & 0 & 41 & 12 & 27 & 27 & 16 & 0 & 18 \\
7 & 0 & 0 & 0 & 12 & 29 & 8 & 12 & 13 & 12 & 16 \\
8 & 0 & 10 & 0 & 17 & 14 & 0 & 40 & 27 & 0 & 17 \\
9 & 17 & 23 & 0 & 20 & 16 & 0 & 22 & 11 & 0 & 33 \\
10 & 10 & 16 & 0 & 23 & 13 & 0 & 12 & 19 & 0 & 10 \\
\hline Mean & 15,5 & 8,1 & 0 & 15,2 & 16,7 & 8,4 & 26,5 & 15,9 & 6,1 & 20,1 \\
St Dev & 10,200 & 8,791 & 0,000 & 12,319 & 6,512 & 9,635 & 9,982 & 4,989 & 8,191 & 7,341 \\
\hline Loc.-localization, Mean - Arithmetic mean, St Dev - Statistical deviation
\end{tabular}

Loc. - localization, Mean - Arithmetic mean, St Dev - Statistical deviation divided randomly into groups of ten and prepared. The crowns of the teeth were sectioned horizontally to expose the dentin tissue. This flat preparation was designed to allow the best possible equality and comparability of the samples. The preparation surface was finished with sandpaper with a roughness corresponding to the yellow diamond bur (Grit P800).

Optibond FL (Kerr, Orange, USA) DBA was applied to the exposed dentin strictly according to the manufacturer's instructions (21). Lingual half of the preparation was covered with a Teflon tape to protect the DBA layer from the sandblasting process. Within each group, two different sandblasters were used: Group 1 - RONDOflex plus 360 (KaVo, Bieberach an der Riss, Germany) and Group 2 - Airsonic Mini-Sandblaster (Hager\&Werken, Duisburg, Germany).

RONDOflex plus 360 was used in the following mode: The lowest pressure recommended by the manufacturer $-3,2$ bar (20), distance from the surface recommended by the manufacturer $-1 \mathrm{~mm}$, powder jet perpendicular to the surface - recommended by the manufacturer, the water jet was activated, five seconds of sandblasting of both Teflon-covered and exposed part of the preparation surface, $50 \mu \mathrm{m}$ grain size.

Airsonic Mini-Sandblaster was used in the following mode: The lowest pressure recommended by the manufacturer -4 bar (19), minimal distance from the surface recommended by the manufacturer $-2 \mathrm{~mm}$, powder jet perpendicular to the surface, water jet not supported by the sandblaster, five seconds of sandblasting of both Tefloncovered and exposed part of the preparation surface, $50 \mu \mathrm{m}$ grain size.

The teflon tape was removed and the prepared surface was covered by Provitemp temporary cement (Itena Clinical, Villepinte, France). The reason for the application of the cement is the protection of the DBA layer during the subsequent processing and enabling the optical observation of the DBA layer, which is relatively translucent.

Subsequently, two vertical preparations were performed perpendicular to the original preparation to detect the thickness of the DBA layer vestibularly (with the influence of sandblasting) and lingually (without the influence of sandblasting). 


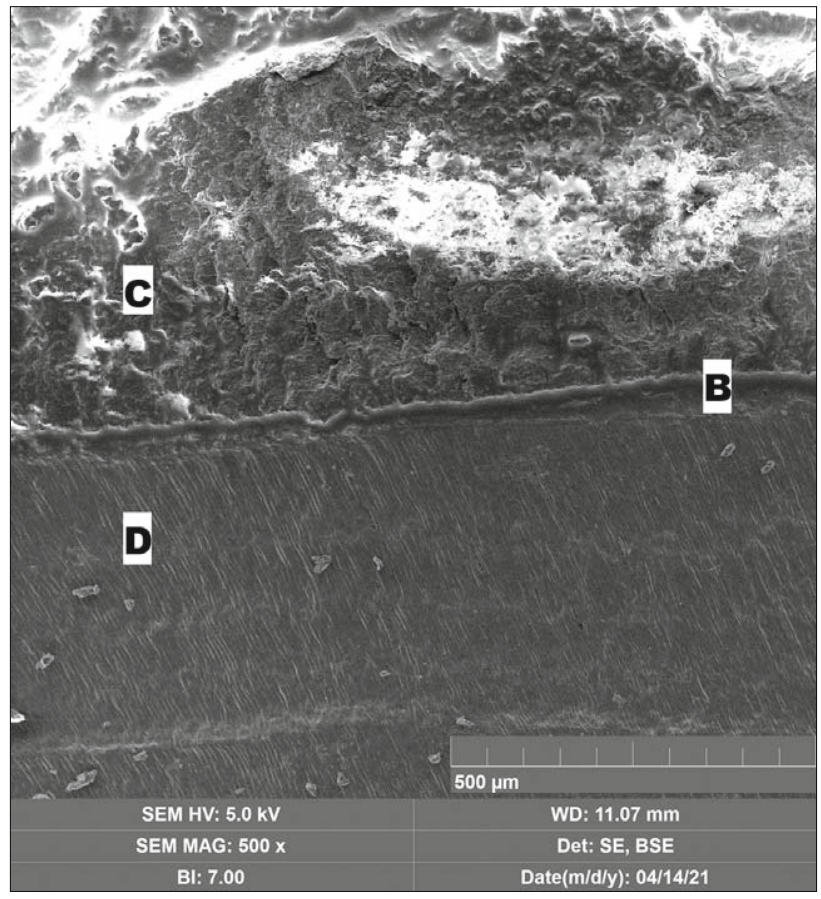

Fig. 1. A SEM image of the DBA layer present after sandblasting on sample num. 1. (B - DBA layer, C - protective temporary cement, D - dentin).

The observations with a digital optical microscope (VHX5000 , Keyence, Japan) with an additional scanning electron microscope control (VEGA 3LMU, Tescan, Czechia) were started at a randomly selected location on the edge of the dentin, and another nine observations were made at locations in predetermined distance from the previous observation.

The Ethics Committee of the University Hospital and the Faculty of Medicine and Dentistry of Palacky University in Olomouc approved this study (Reference number: 159/21).

\section{Statistical analysis}

The arithmetic mean and statistical deviation was used for the statistical analysis. The measurement results were presented in tables and a boxplot.

\section{Results}

The thickness of Optibond FL layer applied according to the manufacturer's instructions is presented in the Tables 1 and 2. The arithmetic mean of the film thickness was 48,72 $\mu \mathrm{m}$ (Group $1=45.55 \mu \mathrm{m}$ and Group $2=51.88 \mu \mathrm{m}$ ) and a significant range of values was recorded (17 to $160 \mu \mathrm{m}$ ).

The DBA layer thickness was reduced to the average value of $17.12 \mu \mathrm{m}$ by RONDOflex plus 360 sandblasting (Group 1). The zero value was recorded in $16 \%$ of the locations. The Airsonic Mini-Sandblaster (Group 2) sandblasting changed the average thickness of the DBA layer to $13,25 \mu \mathrm{m}$ with $31 \%$ of zero val-

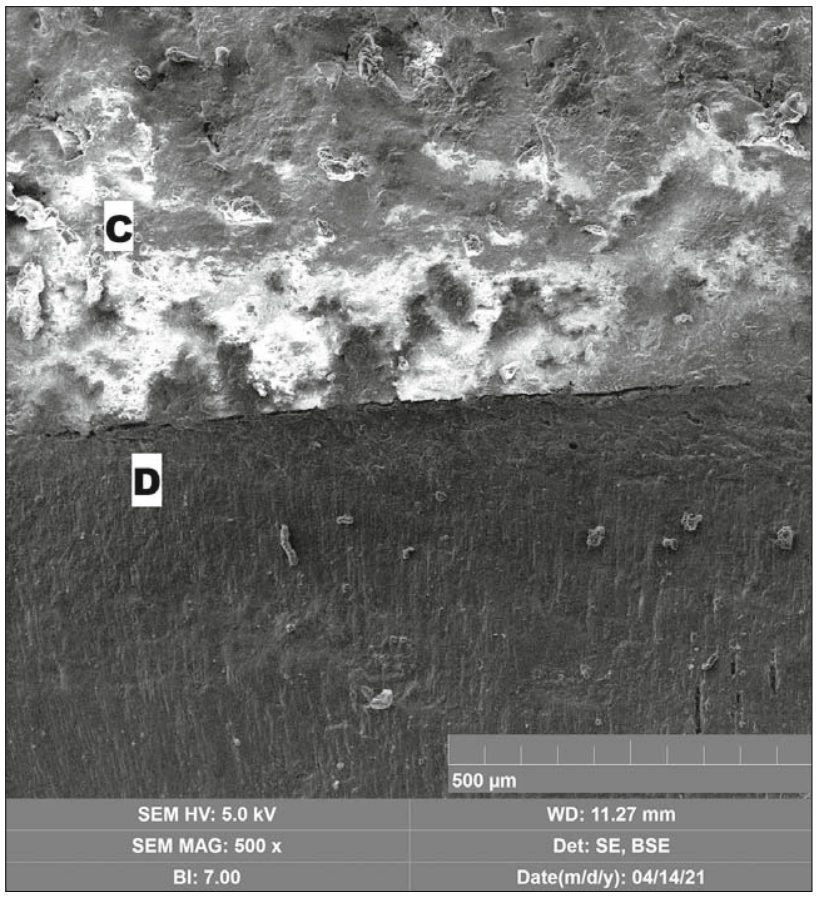

Fig. 2. A SEM image of the DBA layer missing after sandblasting on sample num. 9. (C - protective temporary cement, $D$ - dentin).

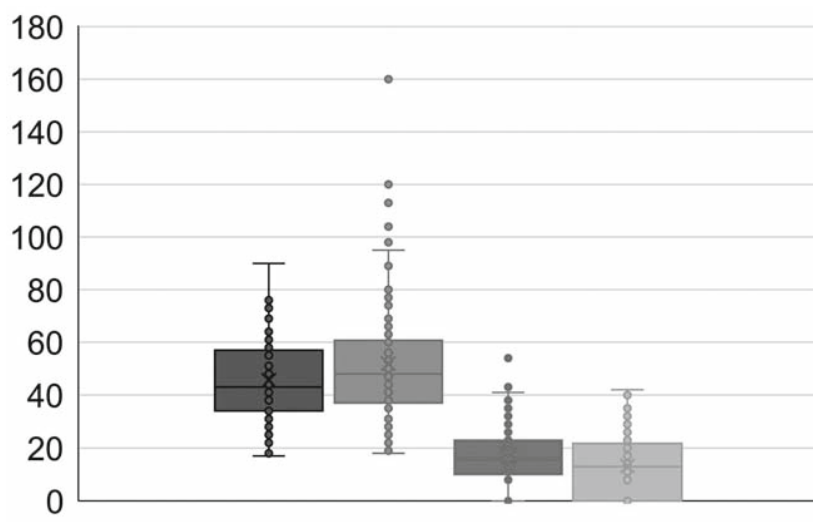

Fig. 3. A boxplot graph of measurements $(\mu \mathrm{m})$. (Group 1, NON SB -protected from sandblasting. Group 2, NON SB -protected from sandblasting. Group 1, SB - RONDOflex plus360, 3,2 bar, sandblasted. Group 1, SB - Airsonic Mini-Sandblaster, 4 bar, sandblasted.)

ues. Sandblasted DBA layer thickness values are presented in the Tables 3 and 4 and Figures $1-3$.

From another point of view, the average observed reduction of DBA layer thickness was $28,43 \mu \mathrm{m}$ for the RONDOflex plus 360 sandblasting and $38,63 \mu \mathrm{m}$ for the sandblasting with Airsonic Mini-Sandblaster. 


\section{Discussion}

This study was designed on a flat dentin surface to obtain the most uniform DBA layer possible. This also helped to compare different sandblasters. The in vivo situations contain a complex of concave and convex surfaces due to the predilection areas of caries. A higher unevenness of the DBA layer thickness is than expected due to the surface tension of the liquid DBA or the relative inaccessibility of the coated surface for air-thinning during the process of applying of the DBA.

Stavridakis et al (22) evaluated the various thickness of the Optibond FL layer of $87.99 \mu \mathrm{m} \pm 73.76 \mu \mathrm{m}$ in a specific set of convex and concave geometry of the onlay cavity. The DBA layer was not air-thinned in this study. Magne et al $(9,23,24)$ stated that the thickness of DBA may vary significantly according to the surface geometry. On average, it was $60 \mu \mathrm{m}$ to $80 \mu \mathrm{m}$ on a convex surface and up to $200 \mu \mathrm{m}$ to $300 \mu \mathrm{m}$ on concave surfaces.

The influence of the cavity geometry may be significant for the possibility of dentin exposure during the sandblasting process due to the thinner DBA layer.

Molin et al (25) studied the influence of the film thickness of the DBA on the joint bond strength of the ceramic - dentin interface and showed that the bond strength values were significantly lower with $20 \mu \mathrm{m}$ film than with $50 \mu \mathrm{m}, 100 \mu \mathrm{m}$ or $200 \mu \mathrm{m}$ films. Sixty-six percent of our measurements after sandblasting were $20 \mu \mathrm{m}$ or lower.

Optibond FL dentin bonding agent was chosen for this study. The properties of this DBA are considered suitable for the purpose of immediate dentin sealing $(22,26,27)$. Optibond FL is one of the highly filled high-viscosity dentin bonding agents and makes a relatively thick layer after applying on the dentin surface compared to most of the other dentin bonding agents.

A relatively large number of factors determine the impact of sandblasting on the DBA layer thickness. In addition to the mentioned cavity geometry, it is also sandblasting duration, the nozzlesurface distance, the abrasion resistance of the DBA material, the sandblasting grain size and the sandblasting pressure.

The sandblasting duration is clearly connected in proportion with the number of particle collisions with the surface of the sandblasted object and thus also with the reduction of the DBA layer. The time influence has been proven, among others, for sandblasting of the enamel (28).

The nozzle-surface distance is a factor due to the air resistance to the sandblasting particle velocity. This factor did not show a difference between the distances of $1-3 \mathrm{~mm}$ (28). A longer nozzle-surface distance resulted in a great area of influence due to the conical scattering of the particles, making it unusable in the oral cavity (28).

The pressure was chosen at the minimum of the manufacturers' requirements due to the fact that the sandblasting with these pressures showed the macroscopic influence on the DBA layer in our pilot studies and due to the risk of a complete loss of the DBA layer while using higher pressures.

From the physical principles, it can be deduced that the enlargement of the sandblasting particles increases their momen- tum, which then transfers more energy to the surface and thus has a greater abrasive efficiency. Likewise, increasing the pressure gives the particles more momentum. These influences should be considered as physical paradigms and their influence in dentistry has not been scientifically measured.

The results of this research lead to the reflection on modifications of the IDS procedure so as not to re-expose dentin, or more simply, to allow binding to re-exposed dentin. Consideration of modifying the IDS procedure may lead us either to use the DBA multiple times or to use the DBA without thinning its layer with pressured air, which may lead to an excessive DBA contraction. Another option would be to use the resin coating procedure. Another type of solution would be not to modify the DBA application process, but to presume the dentin re-exposure and to modify the luting adhesive protocol to allow binding not only to the composite resin and enamel, but also to the freshly re-exposed dentin.

In our study, we investigated the effect of the sandblasting process on the thickness of the IDS layer. In the conditions set by us, it was found that the IDS layer thickness is reduced by sandblasting and in a certain number of cases described above it is completely removed.

\section{References}

1. Soares LM, Razaghy M, Magne P. Optimization of large MOD restorations: Composite resin inlays vs. short fiber-reinforced direct restorations. Dent Mater 2018; 34 (4): 587-597.

2. Bresser RA, Gerdolle D, van den Heijkant IA, Sluiter-Pouwels LM, Cune MS, Gresnigt MM. Up to 12 years clinical evaluation of 197 partial indirect restorations with deep margin elevation in the posterior region. $\mathrm{J}$ Dent 2019; 91: 103227.

3. Hofsteenge JW, Hogeveen F, Cune MS, Gresnigt MMM. Effect of immediate dentine sealing on the aging and fracture strength of lithium disilicate inlays and overlays. J Mech Behav Biomed Mater 2020; 110: 103906.

4. van den Breemer CRG, Cune MS, Özcan M, Naves LZ, Kerdijk W, Gresnigt MMM. Randomized clinical trial on the survival of lithium disilicate posterior partial restorations bonded using immediate or delayed dentin sealing after 3 years of function. J Dent 2019; 85: 1-10.

5. Hayashi K, Maeno M, Nara Y. Influence of immediate dentin sealing and temporary restoration on the bonding of $\mathrm{CAD} / \mathrm{CAM}$ ceramic crown restoration. Dent Mater J 2019; 38 (6): 970-980.

6. Sinjari B, D'Addazio G, Murmura G et al. Avoidance of Interaction between Impression Materials and Tooth Surface Treated for Immediate Dentin Sealing: An In Vitro Study. Materials (Basel) 2019; 12 (20): 3454.

7. Bertschinger C, Paul SJ, Lüthy H, Schärer P. Dual application of dentin bonding agents: effect on bond strength. Am J Dent 1996; 9 (3): $115-119$.

8. Paul SJ, Schärer P. The dual bonding technique: a modified method to improve adhesive luting procedures. Int J Periodontics Restorative Dent 1997; 17 (6): 536-545.

9. Magne P. Immediate dentin sealing: a fundamental procedure for indirect bonded restorations. J Esthet Restor Dent 2005; 17 (3): 144-155.

10. Qanungo A, Aras MA, Chitre V, Mysore A, Amin B, Daswani SR. Immediate dentin sealing for indirect bonded restorations. J Prosthodont Res 2016; 60 (4): 240-249. 
11. van den Breemer CR, Gresnigt MM, Cune MS. Cementation of Glass-Ceramic Posterior Restorations: A Systematic Review. Biomed Res Int 2015; 2015: 148954.

12. Gresnigt MMM, Cune MS, Schuitemaker J et al. Performance of ceramic laminate veneers with immediate dentine sealing: An 11-year prospective clinical trial. Dent Mater 2019; 35 (7): 1042-1052.

13. Nawareg MM, Zidan AZ, Zhou J, Chiba A, Tagami J, Pashley DH. Adhesive sealing of dentin surfaces in vitro: A review. Am J Dent 2015; 28 (6): 321-332.

14. Khakiani MI, Kumar V, Pandya HV, Nathani TI, Verma P, Bhanushali NV. Effect of Immediate Dentin Sealing on Polymerization of Elastomeric Materials: An Ex Vivo Randomized Controlled Trial. Int J Clin Pediatr Dent 2019; 12 (4): 288-292.

15. Hironaka NGL, Ubaldini ALM, Sato F, Giannini M, Terada RSS, Pascotto RC. Influence of immediate dentin sealing and interim cementation on the adhesion of indirect restorations with dual-polymerizing resin cement. J Prosthet Dent 2018; 119 (4): 678.e1-678.e8.

16. Ashy LM, Marghalani H, Silikas N. In Vitro Evaluation of Marginal and Internal Adaptations of Ceramic Inlay Restorations Associated with Immediate vs Delayed Dentin Sealing Techniques. Int J Prosthodont 2020; 33 (1): 48-55.

17. Carvalho MA, Lazari-Carvalho PC, Polonial IF, Souza JB. Significance of immediate dentin sealing and flowable resin coating reinforcement for unfilled/lightly filled adhesive systems. J Esthet Restor Dent 2021; 33: 88-98.

18. https://velopex.com/wp-content/uploads/2020/11/09.20-en-aquacare-single-final.pdf.
19. https://www.hagerwerken.de/wp-content/uploads/2017/01/Airsonic-GBA-Rev8-1020-72dpi.pdf.

20. https://cdn2.hubspot.net/hub/163861/file-295468604-pdf/kavousapdfs/Rondoflex_360_instructions_for_use.pdf.

21. https://kavokerr.widen.net/content/x9wegtqz7i/original/OptiBondFL_IFU_79588_20180131_Rev3_Multi-Language.pdf.

22. Stavridakis MM, Krejci I, Magne P. Immediate dentin sealing of onlay preparations: thickness of pre-cured Dentin Bonding Agent and effect of surface cleaning. Oper Dent 2005; 30 (6): 747-757.

23. Pashley EL, Comer RW, Simpson MD, Horner JA, Pashley DH, Caughman WF. Dentin permeability: sealing the dentin in crown preparations. Oper Dent 1992; 17 (1): 13-20.

24. Magne P, Douglas WH. Porcelain veneers: dentin bonding optimization and biomimetic recovery of the crown. Int J Prosthodont 1999; 12 (2): 111-121.

25. Molin MK, Karlsson SL, Kristiansen MS. Influence of film thickness on joint bend strength of a ceramic/resin composite joint. Dent Mater 1996; 12 (4): 245-249.

26. Magne P. IDS: Immediate Dentin Sealing (IDS) for tooth preparations. J Adhes Dent 2014; 16 (6): 594.

27. van den Breemer CR, Gresnigt MM, Cune MS. Cementation of Glass-Ceramic Posterior Restorations: A Systematic Review. Biomed Res Int 2015; 2015: 148954.

28. Lundgren T, Samuelson A, Clase C, Naoumova J. How sandblasting on lingual surfaces can be carried out with minimum enamel damage: An in vitro study on human teeth. Int Orthod 2020; 18 (4): 820-826.

Received August 24, 2021. Accepted September 21, 2021. 